\title{
Poeticas da negritude e da exclusão em Jorge Amado
}

\author{
Poetics of the black and the exclusion in Jorge Amado
}

Betina Ribeiro Rodrigues da Cunha*

\begin{abstract}
Resumo
Este trabalho pretende observar como Amado escreve em Suor sobre as coisas do homem, do negro e de seu universo real, fictício e idealizado (aos 16 anos, o escritor também morou em um dos sobrados da Ladeira), desenha também um espaço de interação no qual as trocas, as identidades fazem entender de representações mentais, de suas diferenças, de formas de conhecimento individuais e sociais.
\end{abstract}

Palavras-chave: Negritude, exclusão, identidade, cultura, literatura brasileira, ficção.

\begin{abstract}
This paper aims to understand how Amado writes in Suor (Sweat) about the things of men and their real universes, fictional and idealized (at the age of 16, the writer also lived in one of the houses of the Slope), also drawing a space of interaction in which the exchanges and identities promote the understanding of mental representations of their differences in individual and social knowledge.
\end{abstract}

Key-words: Blackness, exclusion, identity, culture, Brazilian literature, fiction.

Recibido: 3 noviembre 2016

Aceptado: 18 enero 2017

No caso da Bahia, qual a marca fundamental? Eu vos diria, Senhora, que essa marca é a mistura. Aqui tudo se misturou, num amálgama colossal. Sangues, raças, religiões, costumes, negros e brancos, índios e mamelucos, ricos e pobres, e mulatos com mulatas, mestiços com mestiças e foi surgindo essa cor de pele e essa consciência democrática, a condição cordial e a doçura, o prazer sensual de cada instante e de todas as minúcias. Ai meu Deus, somos faces somadas, multiplicadas, e dentro de nós, em nosso sangue, as contradições encontraram o caminho da convivência $^{1}$

\footnotetext{
* Brasileira, Professora de Literatura na Universidade Federal de Uberlândia, Dra ${ }^{a}$. em Letras com Pós-
} Doutorado em Literatura Comparada. betina@ufu.br. 
Mundo: Hemisfério Sul, Brasil, Bahia, Salvador, Ladeira do Pelourinho, nº 68.

Visto da rua o prédio não parecia tão grande. Ninguém daria nada por ele. É verdade que se viam as filas de janelas até o quarto andar. Talvez fosse a tinta desbotada que tirasse a impressão de enormidade. Parecia um velho sobrado como os outros, apertado na ladeira do Pelourinho, colonial, ostentando azulejos raros. Porém era imenso. Quatro andares, um sótão, um cortiço nos fundos, a venda do Fernandes na frente, e atrás do cortiço uma padaria árabe clandestina. 116 quartos, mais de 600 pessoas. 2

Um espaço, um lugar, um endereço, uma imagem. Um prédio, na Ladeira do Pelourinho, em Salvador, situa e abriga, nessa desapaixonada descrição, inúmeras lutas, sofrimentos e angústias. Esse sítio histórico, que se confunde com a idéia do mito fundante da Bahia e da terra onde começou o Brasil, como realça Gilberto Freyre em um dos seus poemas sobre uma visita à Bahia - "Bahia/Salvador/São Salvador/Todos os Santos/Tomé de Souza/Tomés de Souza/padres, negros, caboclos/Mulatas quadraronas octorunas/ a Primeira Missa/ os malês/ índias nuas/ vergonhas raspadas"3 - representa um cenário dramático, de face noturna e sombria, significando, muito especialmente nessa obra, uma metáfora das desigualdades sociais, que remontam à escravidão e à função de lugar de tortura dos escravos para, em seguida, evocar a sordidez e a perplexidade como pano de fundo de uma situação social e política sempre devedoras de dignidade e humanização do sujeito. O próprio Jorge Amado, em entrevista a Anne Raillard (1990, p. 33), fala de suas vivências em Salvador, apontando para o lugar emblemático e simbólico do Pelourinho:

Durante algum tempo morei numa ruela vizinha ao Largo do Pelourinho, no coração da velha Bahia, um lugar admirável por sua arquitetura e terrível pelo que significa o pelourinho era o lugar em que eram castigados publicamente os escravos. A casa em que eu morava era uma construção colonial alta e sombria, onde se amontoava uma porção de pessoas exóticas. Eu morava bem em cima, numa água-furtada. Hoje transformaram-na num hotel, juntando dois sobrados, e até colocaram uma placa indicando que é a casa descrita em Suor; é exatamente o que eu mostro nesse romance. Suor é verdadeiramente a minha vida no Pelourinho.

Neste lugar a dialética conteúdo/continente, intuída e reconhecida pela configuração da imagem-endereço inicia e, ao mesmo tempo, sela seu destino em um mesmo ângulo:

\footnotetext{
${ }^{1}$ Jorge Amado, Carta a uma leitora sobre romance e personagens. In: Jorge Amado, Povo e Terra: 40 anos de literatura, São Paulo, Livraria Martins Editora, 1972, p. 28.

${ }^{2}$ Jorge Amado, Obra completa, Vol. 1, Suor, São Paulo, 17 Ed., Editora Martins Fontes, 1968. p. 230.

${ }^{3}$ Gilberto Freyre, Talvez poesia, Belo Horizonte, $3^{\mathrm{a}}$ Ed., Editora Boa viagem, 2014, p. 34.

Obs.: $\mathrm{O}$ título da obra é assim justificado por Freyre em prefácio à mesma obra, p. 25: "Para a reunião em livro desses experimentos de um mau, porém insistente e já velho aprendiz de poeta (que, por amor a tais aventuras, vem às vezes traindo sua prosa, sem substituí-la senão por arremedos de poesia), eu próprio adotei, mais por prudência que por modéstia, o título Talvez poesia".
} 
Mundo. Um olhar que cruza esse mesmo ângulo, ponto de partida e de chegada: mundo.

Um mundo. Um mundo fétido sem higiene e sem moral, com ratos, palavrões e gente. Operários, soldados árabes de fala arrevesada, mascates, ladrões, prostitutas, costureiras, carregadores, gente de todas as cores, de todos os lugares, com todos os trajes, enchiam o sobrado. Bebiam cachaça na venda do Fernandes e cuspiam na escada, onde por vezes, mijavam. Os únicos inquilinos gratuitos eram os ratos4.

Um mundo, macro e micro texto de uma escritura lúcida, permeada de uma única cara, a do homem, do homem que ali vive e trabalha e sua. Assim nasce Suor, título metafórico e exemplarmente sintético, a reunir, na sua ínfima gota, toda uma parcela de sujeitos-objetos e sujeitos-impressões, que delineiam a perspectiva da exclusão sob sua mais consistente e essencial dor.

Suor é o terceiro livro de um, ainda jovem, Jorge Amado. Foi escrito em 1934, aos 22 anos do escritor - na maturidade, este apontava para o obra como o "caderno de um jovem aprendiz". Entretanto, o romance já delineia temas, tipos sociais e preocupações que serão mote para toda uma produção literária, política e para a adesão à ideologia e princípios do comunismo.

Este trabalho pretende observar como Amado, escrevendo sobre as coisas do homem e de seu universo real, fictício e idealizado (aos 16 anos, o escritor também morou em um dos sobrados da Ladeira), desenha também um espaço de interação no qual as trocas, as identidades fazem entender de representações mentais, de suas diferenças, de formas de conhecimento individuais e sociais. Esse mesmo espaço, em contrapartida, chega - de maneira intuitiva, quase paradoxal, poética e, ao mesmo tempo dolorosa na sua crueza - a elevar o papel do negro na sua condição igualmente excludente, como um exercício de respeito e reconhecimento de seu papel para construção deste universo de representações e identidades trincadas.

Nesse sentido, é interessante anotar a importância de se fazer jus à face do negro, não alimentando deturpações que desvalorizam a sua contribuição para a formação da cultura e da identidade nacional, reabilitando, como uma tarefa de toda a comunidade - não só de um escritor - as vozes ancestrais e primitivas da nossa origem e história.

Temáticas específicas do negro tem ocupado bastante espaço nas lutas sociais do Brasil. Aliás, diversos historiadores, antropólogos e estudiosos, poetas e escritores, dentre eles Eduardo de Oliveira e Oswaldo de Camargo, figuras como Bastide, Florestan Fernandes, Sérgio Milliet, Henrique L. Alves ou, ainda, Tristão de Athayde, são nomes graças aos quais se criam instâncias de legitimação da literatura negra em São Paulo com estudos, crítica literária e, sobretudo, devolvendo-lhes o outro lado da história - dessa história "branca" que o tem negado como povo possuidor de valores, culturas, identidade e cidadania.

Talvez por essa universalidade e vocação plural, o termo negritude, a despeito de uma série de interpretações conceituais, marque um espaço de diálogo e pontuação desta

${ }^{4}$ Amado, Op Cit, p. 231. 
presença como um traço a configurar tal reconhecimento.

Para tanto, busca-se um diálogo com os escritores e pensadores de origem francesa, provavelmente os primeiros a usarem o termo "négritude" com esse fim. Criada pelo poeta martinicano Aimé Césaire, a palavra aparece pela primeira vez em Cahier d'un retour au pays natal (1939), considerado por André Breton como um dos maiores "monumentos líricos" em língua francesa, espécie de meditação poética e política, nas quais se entrelaçam, entre ruptura e programa, os fios de uma experiência pessoal e da existência torturada de uma raça. Nessa obra, a palavra "négritude" aparece com três sentidos: a) o povo negro; b) o sentimento ou a vivência íntima do negro; c) a revolta e a consternação, sendo considerada por Lígia F. Ferreira, em brilhante artigo publicado na Revista Via Atlântica", de uma negritude "pacífica", de inspiração nitidamente senhoriana em suas aspirações universalistas, embora preveja a necessidade de se aculturar a diferentes tempos e espaços.

Com um esforço genuíno de resgate e sobrevivência deste negro, Amado, por exemplo, desenha a vendedora de acarajé e outros acepipes baianos:

Ela ocupava quase toda a porta com latas de querosene cheias de mingau e munguzá e o tabuleiro enfeitado de desenhos, coberto com a alva toalha rendilhada, debaixo da qual os acarajés e as moquecas de aratu se acomodavam junto à cuia de barro que levava o molho de pimenta. A preta ficava ali até alta madrugada, quando os últimos negros e mulatos se tinham recolhido e a cidade dormia, fechadas as janelas coloniais, silenciosos os sinos das igreja inúmeras. A carapinha já estava branca e ela sabia histórias velhas como as igrejas, histórias da escravidão, de ioiôs e de iaiás, de escravos e mucamas. Por isso, os pretos moços se sentavam perto dela. 6

Com traços firmes, mas líricos e poéticos, o prosador- político-cidadão estampa uma elegante e sóbria figura, a concentrar um respeito incontestável e uma reverência pela idade e substância quase eternas dessa negra, que guardava, em sua memória, recortes e histórias de uma sensibilidade afogada pelos maus-tratos e pela indignidade. Os pretos moços, ao compartilharem esse universo, tornam-se guardiões e responsáveis pela manutenção de tal patrimônio referencial e simbólico de uma raça, de um povo e de um sofrimento.

Essa mesma negra, em outro momento, presentifica um novo-velho debate e, em uma voz sábia e profética adverte:

No princípio da ladeira, um negro bêbado cantou a trova do escravo:

Xiquexique é pau de espinho,

Umburana é pau de abeia,

Gravata de boi é canga,

${ }^{5}$ Ligia Ferreira, "Negritude", "Negridade", "Negrícia": história e sentidos de três conceitos viajantes", In: Via Atlântica n $^{\circ} 9$ jun/2006, São Paulo, Editora USP, p. 163-185.

${ }^{6}$ Amado, Op Cit., 250. 
Paletó de negro é peia

A negra sorriu:

- Tá vendo?

- Tou. A gente liberta o negro.

A negra ia apanhando o tabuleiro. Henrique ajudou-a a botar as latas vazias em cima. Ela perguntou:

- Você sabe qual a coisa mais melhor do mundo?

- Qual é, minha tia?

- Adivinhe.

- Mulher...

- Não.

- Cachaça ...

- Não.

- Feijoada ....

- Não sabe o que é? É cavalo. Se não fosse cavalo, branco montava em negro...7

A negritude, construída na obra de Jorge Amado acaba por mostrar que o discurso literário de Jorge Amado, sobretudo em Suor, se faz presente a partir de representações carregando um comportamento dialético entre um $\mathrm{Eu}$ e um Outro, entre um estar-ser, entre um passado-presente que torna-se parte de uma necessidade premente - não mais de um desejo ou de uma promessa ou de uma expectativa - de viver. E ser reconhecido

As narrativas são uma prosa fragmentada, que se assemelha a uma sucessão de temas e contos reunidos por um único endereço, Ladeira do Pelourinho, $\mathrm{n}^{\mathrm{o}}$ 68, sobrado com quartos subdivididos até o máximo da promiscuidade, opressivo e desumano respeito ao homem. Este sobrado, objeto simbólico de um cotidiano de miséria, de lixo e de suores, se mistura, fazendo valer - em uma voz polifônica que resgata, dentre tantos tipos excluídos em uma subcondição humana - uma consciência lírica a denunciar a exploração do outro e o caminho revolucionário.

Observa-se assim um lirismo experimentado não mais na dor do coração e das vivências afetivas, mas, sobretudo, um lirismo que aponta para os sentimentos nascidos da dor do cotidiano e do movimento especular que se inicia em um sujeito que se reflete e se reconhece na miséria do outro; um espelho sem face, cuja humanização somente poderá se construir por esse processo de lucidez e reconhecimento da marginalidade e da negritude que, por sua vez, instaura a exclusão como uma verdade inexorável e, entretanto, consolidada por um agenciamento social sempre implacável, retrato em branco e preto de uma realidade cruel e antagônica ao próprio exercício de ser homem.

Em uma dramática pintura dos dramas da coletividade e das massas excluídas, temse, no casarão do $\mathrm{n}^{\circ} 68$, uma enormidade de personagens sem herói; personagens sem destino, sem sentido e dignidade, cujos corpos, grotescos e disformes muitas vezes, anunciam a ausência como um falso paradigma de normalidade e de existência constantemente provisória. Os capítulos, cada um com um nome e um recorte das cenas

${ }^{7}$ Amado, Op Cit, 254. 
vivenciadas nesse lugar - ou contos, como se pode também imaginar as narrativas independentes - refletem, a partir de um espaço urbano bem delimitado, um espaço social, este buscando, por outro lado, desenhar uma ética da existência marginalizada e esquecida: "Os ratos"; "Sótão"; "Gringos"; "Balada"; "Notícia de negro escravo"; "Museu"; "Sexo"; "Diversões"; "Religião"; "Suor"; "Crise"; "K.T. Espero"; "Imigrantes"; "Bodega"; "Palhaços"; "Nomes sem sobrenomes"; "68. Ladeira do Pelourinho"; "Escada"; "Multidão". São, ao todo, 19 títulos que não se referem exclusivamente a um personagem ou situação mas que encenam o dramático cotidiano de inúmeros heróis anônimos, sobreviventes em um espaço de dor e opressão continuadas.

Nesse espaço de provação dos inúmeros tipos, com seus dramas e aprendizados, chama a atenção, inicialmente, a descrição da escada, anunciando um rito de passagem misterioso, obscuro e macabro:

Os ratos passaram, sem nenhum sinal de medo, entre os homens que estavam parados ao pé da escada escura. Era escura assim de dia, e de noite subia pelo prédio como um cipó que crescesse no interior do tronco de uma árvore. [...] De manhã os homens saiam quase todos. $\mathrm{O}$ vozerio das mulheres aumentava. Lavavam roupa. Ruídos de máquinas de costura. A tosse de uma tuberculosa no sótão. Os homens voltavam à tarde, cansados. A escada os devorava um a um. ${ }^{8}$

Tal como uma simbólica esfinge, a escada anuncia não só um local de passagem mas também a passagem para um entre-lugar, a compor uma nova nação construída por discursos múltiplos que desenham uma identidade e a possibilidade de leitura de um outro espaço de enunciação, descentrado dos conceitos cristalizados das culturas oficiais.

Nessa visada, entende-se o ensaio ainda atual de Silviano Santiago quando reconhece que "o intelectual brasileiro, no séc. XX vive o drama de ter de recorrer a um discurso histórico, que o explica, mas que o destruiu, e a um discurso antropológico, que não mais o explica, mas que fala do seu ser enquanto destruição" "O discurso histórico fala aqui por um jovem escritor, Jorge Amado, preocupado com o romance "proletário", um escritor a lembrar que:

Minha geração, êsses romancistas do ano trinta, chegava para a vida e para a criação novelística com o peito oprimido sob a angústia do Brasil e do Homem brasileiro, em busca do caminho para a solução dos nossos problemas. Variados foram os caminhos seguidos, mas o ponto de partida era o mesmo: o amor ao Brasil e ao seu povo, a necessidade de solidarizar-se com o homem e o seu drama, fosse o drama da terra e da fábrica, fosse o drama interior de sua solidão. ${ }^{10}$

Se, por um lado, o escritor vive a experiência do nacional idealizado e de sua identidade, com todas as agruras e lacunas e paixões que a escritura não desvela ou não

\footnotetext{
${ }^{8}$ Amado, op. cit., 229-230.

${ }^{9}$ Silviano Santiago, Vale quanto pesa, Rio de Janeiro, Paz e Terra, 1982, p. 17.

${ }^{10}$ Amado, op. cit., p 13.
} 
antecipa, o Largo do Pelourinho $\mathrm{n}^{\mathrm{o}} 68$ - realidade concreta a ficcionalizar a poética dos excluídos pela marginalidade sem nome - é por si só, um discurso antropológico, que constitui e conserva várias escrituras híbridas, vários sujeitos, de uma condição igualmente híbrida, - todos destruidores da cômoda, padronizada e apaziguadora visão coesa, humanizadora, nacionalista-cidadã.

Importante, nesse caso, realçar a figura do preto Temístocles, figura lendária e misteriosa, que deixou muitas histórias eternizadas pelos moradores do 68 , ao recontarem suas peripécias para os filhos e vizinhos.

Quando saiu, a sua bagagem consistia apenas em fetiches africanos e material para feitiços. As mães relatavam que, no tempo do negro Temístocles, muita gente importante da Cidade subia as escadas cheias de rato para consulta-lo. [... ] No dia de sua mudança, toda a população do prédio se apertou na escada para vê-lo passar. Afirmavam as histórias que ele nascera na África, fizera há muito cem anos e fora escravo em Santo Amaro.

À manifestação de subjetividades primitivas e ancestrais como a referência à origem e religiosidade de Temístocles, emoções e oposições, misturam-se a saberes intermediários, caminhando à margem daqueles já reconhecidos pela cultura vigente e estabelecida, conduzindo, nessa miscelânea ou "contaminação", a uma compreensão da alteridade, ao entendimento do outro e à sua verdade, à ultrapassagem de fronteiras que, necessariamente, abre espaço para um reconhecimento das diferenças e das suas implicações sócioideológicas, morais e culturais.

Nesse espaço, encontra-se, por exemplo, o Judeu mascate, sobrevivente de tantas peripécias e países, vendedor de sombrinhas e sedas falsificadas:

E lá estava no quarto andar do 68 na Ladeira do Pelourinho, naquele mundo de homens de pátrias diferentes e distantes, onde só ele entendia a todos, porque só ele não tinha pátria, nem leis nem deus. ${ }^{12}$

Encontra-se ainda a tuberculosa que, com sua tosse incessante, incômoda a todos os moradores, torna-se um símbolo impotente, mas concreto das mazelas sociais. O sapateiro espanhol, anarquista que queria destruir tudo ${ }^{13}$, convivia com as prostitutas, com o mendigo Cabaça - «Ele também morava no 68, na Ladeira do Pelourinho e, como os ratos, era inquilino gratuito » (S.P.251) - com a surda muda ; o aleijado que trabalhava como palhaço para poder sobreviver, a preta vendedora de acarajé, enfim com todo tipo de pessoas que compunham um "etnopanorama"14 desolador fazendo coexistir uma minoria «nacional »

\footnotetext{
${ }^{11}$ Amado, op. cit., p. 300.

${ }^{12}$ Amado, op. cit., p. 239.

13 ... pegava o gato e levava-o ao pequeno buraco que servia de janela. Olhava a cidade colonial.

- Zug, é preciso destruir tudo isso. Tudo está errado. Zug lambia o nariz.

- Você é um burguês indecente” (Amado, op. cit. 235)

${ }^{14}$ Arjun Appadurai, Disjunção e diferença na economia cultural global, In: Mike Featherstone (org.), Cultura global: Nacionalismo. Globalização e modernidade, Petrópolis, 3.ed., Editora Vozes, 1999, p. 311-327.
} 
incorporada por valores e construções culturais étnicas, políticas e sociais diferentes, sobrevivendo em uma geografia fronteiriça da alteridade indigna e da identidade não reconhecida. A prática desse viver fronteiriço esconde e acolhe, muitas vezes, práticas de sobrevivência inconcebíveis com um modelo forjado de identidade nacional mas, ao mesmo tempo, deixa a entender que o universo apresentado por Amado recusa a idéia de uma nação cristalizada para emergir, segundo Babha ${ }^{15}$ como uma entidade de narrativas e discursos, ambígua e dinâmica. A identidade nacional veiculada em Suor é uma identidade ambígua, ambivalente, cosmopolita, "universalizante", fazendo com que as cenas interiores, localizadas no cortiço, escancarem, na maioria das vezes, o público, o exterior, a dialética do público/privado como também um fator de questionamento dos mecanismos da cultura plural e da multiplicidade de sujeitos nela agentes e envolvidos.

Nesse sentido, o casarão referenda uma nova realidade, podendo definir-se como um novo mundo,

em relação ao papel da linguagem, à construção do sujeito, à teoria da identidade (inclusive gênero, relações interpessoais e reivindicações identitárias) e à concepção da realidade e do conhecimento, no âmbito de uma antropologia urbana, que torna visível uma outra forma de metrópole, difundindo-se nas periferias ingovernáveis e em constante movência, onde se desenham cartografias e se deslocam os lugares institucionais do poder e do governo. ${ }^{16}$

Constitui-se assim um microcosmo em relação à metrópole Salvador/Bahia: uma sociedade de diversidade identitária redimensionando suas fronteiras e fechamentos ao problematizar conceitos como identidade, diferença, igualdade, universalismo, subjetividade, cidadania, ética. Entende-se assim a presença de D. Risoleta, a costureira incansável,

Com a cabeça caída sobre a máquina, deixava ver os cabelos brancos que começavam a dominar os pretos como um partido político fraco que aos poucos vai adquirindo adeptos ${ }^{17}$.

E sua sobrinha, uma sonhadora que, ao conhecer as ideias de Álvaro Lima - ativista político - abandona o ideário burguês

[ ...] Dona Risoleta pedalava sempre, incansavelmente, acompanhada pelo olhar triste de Linda, que foi se esmorecendo aos poucos até dormir com um rapaz rico que a via passar, se apaixonava por ela, casavam-se num dia maravilhoso de sol brando e branda aragem, fila de automóveis, ela de véu grinalda, vestido que a madrinha fizera. ${ }^{18}$

\footnotetext{
${ }^{15}$ Homi Babha, A questão do outro: diferença, discriminação e o discurso do colonialismo, In: H. B. Hollanda (org.), Pós-modernismo e política, Rio de Janeiro, Rocco, 1992.

${ }^{16}$ Arnaldo Rosa Vianna Neto, Multiculturalismo e pluriculturalismo, In: Eurídice Figueiredo, Conceitos de Literatura e Cultura, Niterói 2ª ed., EDUFF/EFJF, 2010, p. 290.

${ }^{17}$ Amado, op. cit., p. 234.

${ }^{18}$ Amado, op. cit., 235.
} 
voltando-se para as causas do proletariado, dos trabalhadores e excluídos. Nesse momento, entende-se, sobretudo, as

\begin{abstract}
"mulheres sem sobrenomes". Marias de nacionalidades as mais diversas. Casadas umas, com maridos que também não possuíam sobrenomes; solteiras outras, magras ou gordas, doentes ou sãs, com um único traço de ligação: a pobreza em que viviam. [...] Mulheres que vendiam frutas, lavavam roupas, trabalhavam em fábricas, costuravam, vendiam o corpo. Mulheres sem sobrenome, mulheres do 68 na Ladeira do Pelourinho e de outros sobrados iguais, para quem os poetas nunca fizeram um soneto, elas simbolizam bem a humanidade proletária que se move nas ladeiras e nas ruas escuras. Tiveram uma frase anônima: - Gente sem nome... Gente sem pai... Filhas da puta. ${ }^{19}$
\end{abstract}

Impondo à prosa um ritmo poético, Amado consolida, por esse fragmento, a crise de identidade sociocultural que afeta a comunidade do casarão. A aposição de um sobrenome, mais do que refletir uma relação de filiação ou união, conduz a uma condição intrínseca de reconhecimento do outro como membro de uma comunidade, conduzindo, por extensão, à percepção de uma existência, cuja identidade se conjuga inicialmente na paternidade para, em continuidade, se consolidar na percepção dialógica do outro que também é sujeito, também pertence a um grupo com o qual dialoga e se identifica esse sujeito. Nesse sentido, não ter sobrenome é, mais do que ser plural, é não pertencer a nenhum grupo, tendo assim, uma identidade forjada no provisório, na negação e no não reconhecimento que o Outro faz de si próprio. Mais uma vez o sobrenome, um dos marcos da identidade nacional - herdada dos portugueses e tão determinante de classes e extratos sociais - passa a referendar a fragilidade dos índices de nacionalidade em favor de referências simbólicas deste não pertencimento, de um descentramento que, finalmente, não atinge somente as mulheres na sua múltipla existência, mas sim a todos: "Gente sem pai... gente sem nome..." configura a não existência, o não ser e a exclusão como certezas irrefutáveis de uma condição social maquiada pelas verdades formalizadas na falsa e cega sociedade consolidada pelas elites.

Compreende-se agora a força e o poder do movimento que eclode na comunidade do casarão a partir da greve de bondes. - «Parece estranho que todo o 68 se visse envolvido nas consequências da greve quando apenas os operários da companhia de bondes estavam nela interessados » (S.p.337) - Essa, abortada por denúncias anônimas, prenunciava um movimento coeso, a partir do qual, os moradores, inflamados por uma sede de justiça, de reconhecimento e de condições adequadas de trabalho, passam a se movimentar, confiando em adesões solidárias e novos valores de identidade e de reconhecimento desta comunidade.

Da escada sentiam todo o movimento da casa. Toufik que gritava no sótão. A voz de seu Fernandez na venda. Os passos da italiana no segundo andar. A moça de azul que saía. O canto das lavadeiras que começavam a abandonar o trabalho.

${ }^{19}$ Amado, op. cit., 324. 
A noite aumentava a escuridão da escada.

Isaac, o judeu, se juntou ao grupo. E explicou a Linda:

-Você não vê? Nós fizemos uma outra escada na casa.

- Como? - o Vermelho não entendia...

- Sim, a escada era a única coisa que ligava os inquilinos... Hoje há outra, a solidariedade que nós despertamos... ${ }^{20}$

A escada - famigerada e ávida esfinge, passagem e simbolismo de um universo opressor e sombrio, acesso ao entre-lugar, a um além-cultural e subjetivo - adquire uma nova função e sai para o exterior, configurando um novo olhar fronteiriço. Aliás, aos olhos de Babha, "Uma fronteira não é o ponto onde algo termina, mas como os gregos reconheceram , [ .. ] é o ponto a partir do qual algo começa a se fazer presente"21. A solidariedade se transforma em passagem para o exterior, determinando a fronteira de um novo espaço, igualmente subjetivo e ordenador; um terceiro espaço, uma «terceira margem », não mais aquela de uma Salvador ambivalente e nacional, não mais aquela de um $\mathrm{n}^{\circ} 68$, plural, provisório e sem identidade, mas sim a terceira margem da busca pela dignidade, pela cidadania, pelo respeito ao outro e pelo reconhecimento de si e de uma identidade - múltipla e miscigenada, mas identidade.

Jogaram manifestos. Moças nas janelas. Parecia até uma festa. O rosto magro do propagandista de produtos domésticos. Ouviram-se gritos em árabe. Outros em espanhol. Seu Fernando fechara a venda. O cabelo bem alisado do violinista e a barba por fazer do Toufik. Todo o 68 ali estava. Descera as escadas como um só homem. ${ }^{22}$

Essa fronteira, que agora localiza, extramuros, seus limites pelo exercício humanizado de uma nova subjetividade em construção, concretiza as relações interpessoais acima de um território geopolítico, de uma raça, de um gênero ou de uma orientação, fazendo valer a diferença cultural como instrumento de um novo campo subjetivo, organizador de novos signos de identidade, contestação e inovação face à sociedade .

Assim, compreende-se igualmente o antológico e poético embate entre os moradores e os investigadores:

Os investigadores vinham do terreiro, subiam da Baixa dos sapateiros. A primeira bala se perdeu entre as pedras da rua. A multidão não fugiu. A segunda derrubou a surda-muda, que soltou um som horroroso de maldição. Álvaro Lima gritou: Proletários de todas as nações...

A bala pegou na testa, ele caiu em cima de Linda. A moça sentiu o sangue no rosto e no vestido. Mas não teve medo, nem se moveu.

Então a multidão avançou para os investigadores, de braços levantados. ${ }^{23}$

\footnotetext{
${ }^{20}$ Amado, op. cit., 337.

${ }^{21}$ Homi Babha, O local da cultura, Belo Horizonte, Editora da UFMG, 1998. p.19.

${ }^{22}$ Amado, op. cit., 339.

${ }^{23}$ Amado, op. cit., 339.
} 
A morte de Álvaro Lima, perpassada de um forte cunho ideológico-socialista silenciado emblematicamente, como foi sua formação, passa a ser sinal de vida, de busca, de reconhecimento e de verdade. Uma nova narrativa se impõe, marcando simbolicamente, as cenas discursivas desta nova identidade, não mais alicerçada na Ladeira do Pelourinho $\mathrm{n}^{\circ}$ 68, mas sim no espaço edificado e reinventado pela identidade entrevista nas promessas proletárias e nas promessas de dignidade e cidadania imprimidas no discurso da valorização do sujeito, do indivíduo.

Dessa forma - e pensando mais especificamente nas poéticas romanescas de Jorge Amado e em suas implicações políticas - acredita-se poder observar em Suor uma adesão, ainda idealizada, do escritor ao movimento comunista, o que se desenvolverá com mais densidade a partir dos outros romances.

Em Suor, visto talvez equivocadamente como romance de aprendiz, desenha-se um panorama social que, fazendo reconhecer as antinomias e dialéticas do exercício das subjetividades, antecipa - ainda de modo idealizado e provavelmente utópico ${ }^{24}$ - as saídas possíveis para as situações antagônicas que se resumem no duro exercício de viver. Com toda a descrição árida e penosa dos personagens e de suas condições, com toda a multiplicidade de cenas surpreendentes e assustadoramente realistas, a partir de um naturalismo crítico $^{25}$, sem nuances, expondo a anarquia e o não viver, sobrevive nessa obra a poética da exclusão como uma possibilidade de salvação deste mundo tão indiferente.

Se Cacau, nas palavras de Jorge Amado, pretende ser um romance proletário, tal como afirma em nota à sua edição de 1933:

Tentei contar neste livro, com um mínimo de literatura para um máximo de honestidade, a vida dos trabalhadores das fazendas de cacau do sul da Bahia. Será um romance proletário ${ }^{26}$

ouso inconcluir essas observações pensando em Suor não ainda como um romance proletário mas sim um visionário romance do épico humano, no qual a ação proletária pode ser empreendida como uma possibilidade de salvação e de reconstrução de um universo socioeconômico e cultural baseado em outras relações que não aquela do poder, do colonizado/colonizador, da metrópole/colônia e, mais atualmente, do primeiro mundo/terceiro mundo. Aliás, Silviano Santigo, em Uma literatura nos trópicos, adverte que

o imaginário, no espaço do neocolonialismo, não pode ser mais o da ignorância ou da ingenuidade, nutrido por uma imaginação simplista dos dados oferecidos pela experiência do autor, mas se afirmaria mais e mais como uma escritura sobre outra

\footnotetext{
${ }^{24}$ Adjetivo emprestado do título da obra de Eduardo Assis DUARTE, Jorge Amado: romance em tempo de utopia, Rio de Janeiro, Record, 1996, 227 p.

${ }^{25}$ Tati Miércio, Estilo e revolução no Romance de Jorge Amado, In: Jorge Amado, Povo e Terra: 40 anos de Literatura, Rio de Janeiro, Martins Editora, 1972, p. 125.

${ }^{26}$ Amado, op. cit, p. 121.
} 
escritura. $^{27}$

permitindo ao leitor entender Suor como uma tarefa da poética e humanizada lucidez do escritor, a investir na construção de uma escritura-leitura igualmente lúcida, nascida da denúncia de um cotidiano social desregrado, sem nenhuma identidade que aponta para a construção de uma moral solidária entre os moradores, excluídos grotescamente dignos da Ladeira do Pelourinho, $\mathrm{n}^{\circ} 68$.

Enfim, e interrompendo esse recorte oblíquo de uma condição plural, pode-se intuir portanto que até então não existe romance proletário, existe a escritura sensível de uma escritura sociocultural; um romance que acredita no homem e nas suas causas e que, a partir de uma reconstituição das identidades subjetivas e plurais que o homem Carrega, permite comungar essências unificadoras de valores e diferenças maiores, passiveis de se resolver utopicamente ? - no entendimento da alteridade e da ideologia, ainda que escritural.

\section{Bibliografia}

Alice Raillard, Conversando com Jorge Amado, Rio de Janeiro, Record, 1990.

Arjun Appadurai, Disjunção e diferença na economia cultural global, In:, Mike Featherstone (org), Cultura global, Nacionalismo,Globalização e modernidade, 3.ed., Petropólis, Vozes, 1999.

Arnaldo Rosa Vianna Neto. Multiculturalismo e pluriculturalismo. In: Eurídice Figueiredo, Conceitos de Literatura e Cultura, 2 ed., Niterói, EDUFF/EFJF, 2010.

Eduardo Assis Duarte, Jorge Amado: romance em tempo de utopia, Rio de Janeiro, Record, 1996.

Eurídice Figueiredo, Conceitos de Literatura e Cultura, 2 ed., Niterói, EDUFF/EFJF, 2010. H.B Hollanda (org.), Pós-modernismo e política, Rio de Janeiro, Rocco, 1992.

Homi Babha, A questão do outro: diferença, discriminação e o discurso do colonialismo, In: H.B. Hollanda (org.), Pós-modernismo e política, Rio de Janeiro, Rocco, 1992.

Homi Babha, O local da cultura, Belo Horizonte, Ed. UFMG, 1998.

Jorge Amado, Discurso de posse na Academia Brasileira de Letras, In: Jorge Amado, Povo e Terra, 40 anos de Literatura, Rio de Janeiro, Martins Editora, 1972.

Jorge Amado, Obra completa, Vol. 1, Suor, 17 $7^{\text {a }}$ Ed., São Paulo, Editora Martins Fontes, 1968.

Jorge Amado, Povo e Terra, 40 anos de Literatura, Rio de Janeiro, Martins Editora, 1972.

Miércio Tati, Estilo e revolução no Romance de Jorge Amado, In: Jorge Amado, Povo e Terra, 40 anos de Literatura, Rio de Janeiro, Martins Editora, 1972.

Mike Featherstone (org), Cultura global, Nacionalismo, Globalização e modernidade, 3.ed, Petropólis, Vozes, 1999.

Silviano Santiago, Uma literatura nos trópicos, São Paulo, Perspectiva, 1978.

Silviano Santiago, Vale quanto pesa, Rio de Janeiro, Paz e Terra, 1982.

\footnotetext{
${ }^{27}$ Silviano Santiago, Uma literatura nos trópicos, São Paulo, Perspectiva. 1978, p. 17.
} 